\title{
O COVID19 EXPLICITA A COLONIALIDADE DO NOSSO PROJETO DE MODERNIDADE
}

\author{
LARA, FERNANDO \\ Potter Rose Professorship of Urban Planning; Director of PhD Program in Architecture, University of Texas at Austin; fernandolara@utexas.edu
}

\begin{abstract}
INTRODUÇÃO
Antes de mais nada, agradeço ao Grupo Projetar/UFRN pelo convite para conversar com vocês em julho/2020 e publicar este texto na Revista Projetar. Reafirmo aqui o carinho que sinto por essa instituição, que sempre esteve próxima da minha carreira, começando com primeiro Seminário Projetar, em 2003, no qual tive a honra de servir no Comitê Científico e, ainda, organizar um livro ${ }^{1}$ com Sonia Marques, juntando contribuições de outros membros do Comitê Científico. Antes do Projetar de 2003 o único livro brasileiro dedicado a ensino de projeto tinha sido organizado por Carlos Eduardo Comas², duas décadas antes. Tenho muito orgulho de ter contribuído para esse evento, que hoje é um sucesso consolidado na discussão do ensino de Projeto, já caminhando para sua décima edição.
\end{abstract}

O PPGAU da UFRN também me proporcionou uma das maiores alegrias da minha vida acadêmica: Amélia Panet (orientada por Maísa Veloso) escreveu sua tese de doutorado discordando de uma afirmação que Sônia e eu fizemos no livro de 2003. Não vejo elogio maior do que uma pesquisadora dedicar cerca de 5 anos de sua vida para debater uma assertiva minha. O fato é tão raro e tão importante que, como tréplica, em 2015 Sônia e eu organizamos outro livro, o "Quid Novi" ${ }^{3}$, e convidamos Amélia Panet a contribuir com um capítulo.

O ano de 2015 também foi marcado pela publicação do livro Modern Architecture in Latin America, que escrevi com Luis Carranza. Considero que esta é minha maior contribuição para o campo da arquitetura e do urbanismo até o momento. O livro e a exposição que criamos foram apresentados em 28 cidades entre 2015 e 2018, o que me deu a oportunidade de viajar e discutir a história da arquitetura da América Latina de New York a Santiago, de Ciudad de México a Moscou. Nesta trajetória me tornei mais americanista e aprofundei minhas leituras sobre uma teoria decolonial que eu já conhecia, mas que ainda não tinha costurado com a teoria da arquitetura. Me debrucei sobre questões de teoria porque me incomodava a posição de "latino americanista" que eu próprio havia criado. Estudar apenas a parte latina das Américas me parece insuficiente para tratar questões de projeto do nosso continente, porque as Américas têm muito mais em comum do que o que é comumente aceito, e isto incomoda.

Quando, em 2018, me chamaram para dirigir o doutorado aqui em Austin, minha proposta foi criar um núcleo que estudasse as relações espaciais nas Américas, do Alaska ao Chile. Pensei nesta estratégia de linha mestra do doutorado porque nós temos um déficit de conhecimento do nosso próprio território. Em um curso que ministro para a graduação, peço aos alunos que imaginem como o espaço onde eles cresceram, era há 500 anos atrás. Como era, no ano 1520, o quadrilátero ferrífero onde eu cresci? Eu nunca aprendi isto na escola, tive de correr atrás da informação depois de já ser um professor com doutorado.

No dia em que conversamos online combinando essa roda de conversa (em julho de 2020) foi publicado um artigo na Nature provando que o Homo Sapiens está no continente americano há mais de 30 mil anos, o que derruba a ideia de que os primeiros seres humanos vieram para as Américas pelo estreito de Bering durante a última Era Glacial. A descoberta de evidências provando que seres humanos chegaram até aqui navegando pelo Pacífico, e à cerca de 15 mil anos, antes do início da última glaciação, coloca em xeque a maneira como nós temos contado a história do mundo.

A narrativa hegemônica dos últimos 200 anos foi muito centrada na Europa do Norte, em detrimento das nossas raízes Mediterrâneas. O que ficou de Mediterrâneo nessa história do mundo Eurocêntrica foi só Grécia e Roma, o resto foi completamente descartado, principalmente a influência Islâmica e todas as outras civilizações dessa parte do mundo de onde vários de nós descendemos.

Mas sabemos muito, muito pouco sobre quem estava aqui antes. É fundamental, por exemplo, escutar Ailton Krenak, importante líder indígena brasileiro. Krenak ${ }^{4,5}$ nos lembra, o tempo todo, que existem outras cosmovisões que não se encaixam na narrativa ocidental eurocêntrica, que a partir do século XX passou a ser "OTANcentrica" - uso este termo desde que, em 2005, desenhei um mapa com a localização dos edifícios 
retratados nos livros de Kenneth Frampton, William Curtis, Jean Louis Cohen e Vincent Scully, onde se explicita a prevalência das arquiteturas do Atlântico Norte. Por isso, nos últimos anos tenho me dedicado a puxar esses fios do que significa habitar as Américas, do que significa construir, modificar o ambiente das Américas. É sobre isso que pretendo falar.

\section{PANDEMIAS E POPULAÇÕES NATIVAS}

Esse nosso continente americano que tem presença humana há 30 mil anos; depois chegaram os europeus e, com eles, o protagonismo dos nossos antepassados espanhóis e portugueses. Junto com este protagonismo vieram as duas grandes tragédias americanas: holocausto ameríndio que causou uma redução populacional de $90 \%$ ao longo do século XVI; e a escravidão nos três séculos subsequentes. Estas duas tragédias ocorreram em maior ou menor grau por todas as Américas, do Alasca até o Chile. O extermínio dos povos ameríndios por alguma pandemia faz uma ponte para questões bem contemporâneas.

Hoje estamos profundamente abalados e ameaçados por um vírus cuja mortalidade está abaixo de $1 \%$. Entre 1500 e 1600, o sarampo, a catapora e a gripe mataram 90\% da população das Américas. A ocupação colonial que se seguiu foi baseada na escravidão, que reduziu o ser humano a uma propriedade e, a partir daí, nós temos todos os grandes dramas das Américas: o drama da violência, o drama das desigualdades de gênero, das desigualdades de raça, as questões linguísticas, etc... Atualmente, tenho me dedicado a tentar entender o desdobramento destas questões no espaço, porque considero que o conhecimento da civilização ocidental, embora seja fundamental para nós, também é insuficiente, pois não consegue abarcar todos os graus de complexidade da vivência nas Américas. E nós temos que trabalhar estas insuficiências: trabalhar a questão da mulher, metade da humanidade que também foi apagada da história; trabalhar a questão dos povos nãobrancos, não-europeus. Tudo isso tem que ser remontado e retrabalhado na história de quem somos nós.

Tudo isto me ajuda a pensar a pandemia do Covid como um importante divisor de águas. Todos nós (que ainda vamos viver algumas décadas), nossos filhos e netos (que ainda vão viver muitas décadas), vamos sempre nos lembrar do ano de 2020 como o ano da pandemia, porque essa vai ser 'a marca'. Vejamos a comparação com fatos do final do século XX que já vivemos, como a queda do muro de Berlim, a implementação da comunidade europeia, a criação do Mercosul, a breve diminuição das desigualdades no Brasil entre 2003 e 2012 com os governos Lula e Dilma. Todos estes eventos foram muito marcantes, mas a pandemia do Covid já se apresenta claramente como a marca maio; e vai ser a marca maior porque sacudiu as estruturas de um capitalismo tardio que, aliás, já vinha sendo questionado há algumas décadas.

Não vou entrar na questão geopolítica global porque há quem entenda muito melhor do que eu a questão da China e da Índia como novos centros de um poder global que claramente está se deslocando de volta para o Oriente. Quero tratar aqui da questão das Américas e do impacto dessa pandemia. A primeira coisa que essa pandemia revelou foi a absurda desigualdade da nossa estrutura econômica e social. Os trabalhadores mais essenciais, as pessoas que mais contribuem para suportar a base da nossa sociedade, são justamente os menos reconhecidos. Falo aqui das empregadas domésticas, das cuidadoras, dos motoristas de ônibus, dos operários da construção civil. Os menos remunerados e os menos valorizados, estes sim são essenciais. E a pandemia nos chamou atenção para isso. Eles são os que não têm o privilégio de ficar em casa, porque o trabalho deles não pode ser feito de casa, como o meu pode.

Até agora consegui manter a minha produtividade com uma variação mínima, inclusive adicionando alguns luxos, como escutar Teresa Cristina cantando à noite ou estar presente na live do Ailton Krenak. Ontem mesmo minha filha estava escutando Edward Snowden no estágio dela, alguém que eu nunca teria a chance de escutar ao vivo antes dessa pandemia. É fundamental reconhecer que a pandemia do COVID não atrapalhou muito a vida da classe alta intelectualizada, mas, para quem faz o trabalho de base na sociedade, não apenas o risco é maior como eles não têm escolha. A maioria da população não tem escolha, tem que pegar ônibus todo dia e ir trabalhar. Isso ficou claríssimo e a sociedade vai ter que dar resposta a essas questões.

Entrando um pouco na arquitetura, cabe lembrar que somos nós que desenhamos a cidade desse jeito. Em junho de 2020, assistimos horrorizados à morte do menino Miguel, ao cair de uma torre no Recife (Pernambuco). A morte de Miguel explicitou todas essas desigualdades, todas essas escolhas, eu diria imorais, que a sociedade fez nos últimos anos. A mãe do Miguel não deveria estar trabalhando. A patroa do Miguel não deveria estar fazendo unha. E um menino de 5 anos não deveria, nunca, ser deixado sozinho no elevador. Mas ai também vem a nossa responsabilidade como arquitetos, porque nós naturalizamos isso. Naturalizamos espaços como o quarto de empregada com 1,70m por $2,30 \mathrm{~m}$ e sem janela. Somos nós que desenhamos elevadores de serviço, portas de serviço. E isto está na raiz do nosso conhecimento, não é um problema do mercado imobiliário somente. 
A maravilhosa casa de vidro da Lina Bo Bardi tem 3 quartos de empregadas, e isso para servir a um casal sem filhos. Essas desigualdades, essas imoralidades, estão naturalizadas na própria historia da arquitetura e está mais do que na hora de discuti-las.

Na questão do trabalho, nós temos maravilhosos edifícios de arquitetura moderna. É um patrimônio gigantesco ao qual muitos de nós dedicamos décadas a estudar e celebrar. Lendo toda esta bibliografia quase ninguém menciona que todos eles foram construídos com madeira de desmatamento antes de serem preenchidos com o concreto ainda líquido. Ninguém menciona que quem preencheu, quem fez a fôrma, quem carregou o concreto nas costas, quem desformou esses edifícios, foram brasileiros com baixa escolaridade, a maioria deles negros e mulatos. Essa variável ainda não entrou na nossa conversa sobre arquitetura; ainda é uma questão muito periférica que precisa ser incorporada no nosso discurso.

Saindo da escala do objeto arquitetônico para a escala da cidade, nós - urbanistas, desenhadores, planejadores urbanos -, desenhamos uma cidade com profunda desigualdade, uma cidade que concentra equipamentos nas áreas mais ricas, beneficiando apenas quem pode pagar mais.

Claro que o arquiteto e o urbanista, não têm poder político para mudar uma estrutura social, mas temos o poder de denúncia. Podemos dizer: essa ideia de colocar os mais pobres na periferia distante e obrigá-los a, todo dia, ficar três ou quatro horas dentro de um ônibus, simplesmente não pode dar certo. Isto não tem como dar certo. Assim, temos um desafio urgente, acelerado pela pandemia do Covid, que é o transporte público no Brasil. Os números de usuários do transporte público já vinham caindo, sendo disputados pelos aplicativos como Uber, em parte porque o transporte público é caro e ruim, e em parte porque o automóvel traz certo status que reverbera na vida das pessoas.

Como redesenhar essa cidade após o Covid? Depois que controlarem o número de casos, se as pessoas continuarem tendo medo do transporte público teremos uma retomada econômica com gigantesco problema de mobilidade, além de tantos outros.

\section{FINALIZANDO}

Junto com esses grandes desafios de desenhar uma sociedade mais justa, vem a minha parte do trabalho como professor historiador, que é de montar uma outra narrativa para que consigamos, ao menos, indicar caminhos mais inclusivos para a nossa profissão de arquitetura e de urbanismo. Porque, infelizmente, nós passamos muito tempo vendendo exclusividade. Você abre qualquer propaganda de venda de imóveis e a exclusividade é uma forte variável de venda. Você abre qualquer livro de história da arquitetura e a maioria dos edifícios são celebrados pela sua exclusividade; raríssimos são celebrados pela sua reprodutibilidade e, menos ainda são celebrados por terem sido disseminados para além dos limites da profissão.

É hora de tomarmos consciência de que não existe exclusividade sem exclusão. A exclusividade só é alcançada quando um grupo de pessoas é excluído. Eu acho que o Covid fez isso ficar bastante explícito e espero que a gente tenha folego para responder a este desafio.

\section{NOTAS}

${ }^{1}$ LARA, Fernando; MARQUES, S. (Orgs.). Desafios e conquistas da pesquisa e do ensino de projeto. Rio dee Janeiro: EVC, 2003.

${ }^{2}$ COMAS, C. E. (Org.) Projeto Arquitetônico: disciplina em crise, disciplina em renovação. São Paulo: Editora Projeto, 1986.

${ }^{3}$ LARA, Fernando; MARQUES, S. (Orgs.). Quid Novi? architectural education dilemmas in the 21st century, Austin: Nhamerica Press, 2015. (Ganhador do Prêmio Anparq 2016 de melhor livro coletânea).

${ }^{4}$ KRENAK, A. Ideias para adiar o fim do mundo. São Paulo: Companhia das Letras, 2019.

${ }^{5}$ KRENAK, A. O amanhã não está à venda. São Paulo: Companhia das Letras, 2020.
}

NOTA DO EDITOR (*): O conteúdo do artigo e as imagens nele publicadas são de responsabilidade do(s) autor(es). 